\title{
Relation Between the Rheumatoid Arthritis and Certain Oral Manifestations
}

Paixão, T.S'; Cândido, L.L.P1; Almeida, A.V.T; Vasconcelos, E.R.L '; Costa, T.G'; Silva, J.M.N2

Estudante do Curso de Odontologia-UFPE; ${ }^{2}$ Cirurgião Dentista FOP/UPE

\section{ABSTRACT}

Introduction: The oral healthiness is a key component to the overall healthiness of the individual. Among numerous diseases and oral healthiness problems the Sjögren Syndrome, periodontal diseases and temporomandibular joint dysfunction have an important relation with the rheumatoid arthritis that is characterized by the joint inflammation. Objetive: The objetive of the current research is to emphasize the importance of the systemic healthiness with oral healthiness in order to enhance a possible relation between the rheumatoid arthritis and certain oral manifestations. Methodology: This research is constituted of a review of a specialized literature, whom made by search of selected scientific papers from scielo, pubmed and lilacs database. Results and Discussion: Despite lot of researchs made about the impact of oral diseases on the systemic healthiness, the literature about the relation between they still, in majority,inconsistent, and the researchs, in general, have not an effective proof about the direct relation between oral diseases mentioned and the rheumatoid arthritis. Conclusion: It is crucial to highlight that even if have a understanding about the relation between the systemic disease and oral manifestations, there isn't any evident proof of they.
*Correspondence to Author:

Paixão, T.S

Estudante do Curso de Odontologia-UFPE

How to cite this article:

Paixão, T.S, Cândido, L.L.P; Almeida, A.V.T; Vasconcelos, E.R.L; Costa, T.G; Silva, J.M.N. Relation Between the Rheumatoid Arthritis and Certain Oral Manifestations. International Research Journal of Otolaryngology, 2018, 1:3

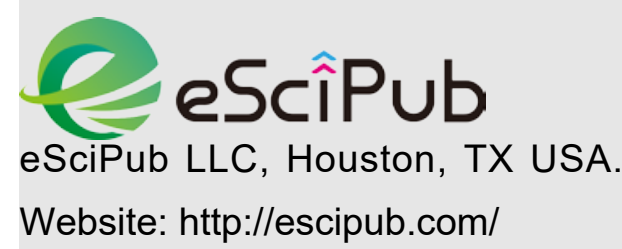

Keywords: Oral Manifestations; Periodontal Disease; Rheumatoid arthritis. 